\title{
CHARACTERIZATION OF PHOSPHORUS SEGREGATION IN NEUTRON-IRRADIATED PRESSURE VESSEL STEELS BY ATOM PROBE FIELD ION MICROSCOPY
}

M. K. MILLER, R. JAYARAM AND K.F. RUSSELL Metals and Ceramics Division, Oak Ridge National Laboratory, P.O. Box 2008, Oak Ridge, TN 37831-6376

\begin{abstract}
An atom probe field ion microscopy characterization of A533B and Russian VVER 440 and 1000 pressure vessel steels has been performed to determine the phosphorus coverage of grain and lath boundaries. Field ion micrographs of grain and lath boundaries have revealed that they are decorated with a semi-continuous film of discrete brightly-imaging precipitates that were identified as molybdenum carbonitride precipitates. In addition, extremely high phosphorus levels were measured at the boundaries. The phosphorus segregation was found to be confined to an extremely narrow region indicative of monolayer-type segregation. The phosphorus coverages determined from the atom probe results of the unirradiated materials were in excellent agreement with predictions based on McLean's equilibrium model of grain boundary segregation. The boundary phosphorus coverage of a neutron-irradiated weld material was significantly higher than that observed in the unirradiated material.
\end{abstract}

\section{INTRODUCTION}

Since the pressure vessel of a nuclear reactor is exposed to elevated temperatures and a flux of neutrons for extended periods, there is the possibility that changes in the microstructure will occur during service that may cause the steel to become embrittled. It is important to be able to measure and accurately predict these changes so that the integrity of the pressure vessel is guaranteed and the possibility of extending the lifetime of the pressure vessel may be estimated. Atom probe field ion microscopy is one technique that provides sufficient resolution to enable these changes to be experimentally measured. This ultrahigh resolution technique enables solute clustering, precipitation and solute segregation to lattice defects including lath and grain boundaries to be directly characterized. ${ }^{1,2}$ Details of the atom probe technique may be found elsewhere. ${ }^{3}$

One common element present in pressure vessel steel that is well known to render steels susceptible to temper embrittlement is phosphorus. In this paper, experimental atom probe characterizations of the phosphorus coverage at lath and grain boundaries in some A533B and Russian $15 \mathrm{Kh} 2 \mathrm{MFA}$ steels are compared to the predictions estimated by the McLean model of equilibrium segregation.

\section{EXPERIMENTAL}

The nominal compositions of the steels used in this investigation are summarized in Table 1. The Russian 15Kh2MFA (VVER 440) and 15Kh2NMFA (VVER 1000) steels are significantly different from their Western counterparts in that they contain much higher levels of chromium and vanadium and slightly higher levels of molybdenum. The A533B was examined in the unirradiated state after a thermal aging treatment of $566 \mathrm{~h}$ at $288^{\circ} \mathrm{C}$ and also after neutron irradiation to a fluence of $1 \times 10^{19} \mathrm{n} \mathrm{cm}^{-2}(\mathrm{E}>1 \mathrm{MeV})$ at a temperature of $288^{\circ} \mathrm{C}$. The Russian $15 \mathrm{Kh} 2 \mathrm{MFA}$ Weld 28 steel was examined in the unirradiated condition after typical thermal heat treatment to produce precipitation hardening ${ }^{4}$ and also after neutron-irradiation to a fluence of $1 \times 10^{19} \mathrm{n} \mathrm{cm}^{-2}(\mathrm{E}>1 \mathrm{MeV})$ with a flux of $4 \times 10^{11} \mathrm{n} \mathrm{cm}^{-2} \mathrm{~s}^{-1}$ in the Rovno Unit 1 reactor at a temperature of $\sim 290^{\circ} \mathrm{C}$. The Weld 37 and the VVER 440 and VVER $10008 \mathrm{~kg}$ laboratory melts were only examined in the unirradiated state.

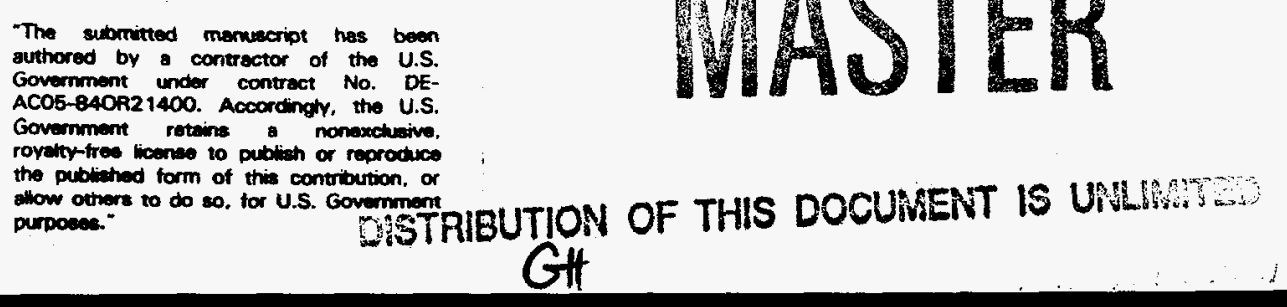


Table I. Nominal composition of the steels used in this investigation. The balance of these compositions is iron and the compositions are given in atomic percent.

\begin{tabular}{|lllll|}
\hline Element & A533B & Weld 28 \& 37 & VVER 440 & VVER 1000 \\
\hline Chromium & 0.05 & 1.71 & 2.77 & 2.48 \\
Molybdenum & 0.25 & 0.37 & 0.39 & 0.34 \\
Vanadium & - & $\mathbf{0 . 2 0}$ & $\mathbf{0 . 3 3}$ & $\mathbf{0 . 1 1}$ \\
Copper & $\mathbf{0 . 3 5}$ & $\mathbf{0 . 1 1}$ & $\mathbf{0 . 3 0}$ & $\mathbf{0 . 0 5}$ \\
Nickel & $\mathbf{0 . 5 7}$ & $\mathbf{0 . 1 4}$ & $\mathbf{0 . 0 7}$ & $\mathbf{1 . 1 5}$ \\
Manganese & 1.37 & 0.95 & 0.36 & 0.41 \\
Silicon & 1.01 & 0.69 & 0.36 & 0.49 \\
Carbon & 0.55 & 0.23 & 0.67 & 0.79 \\
Phosphorus & $\mathbf{0 . 0 1 1}$ & $\mathbf{0 . 0 4 5}$ & $\mathbf{0 . 0 3 2}$ & $\mathbf{0 . 0 1 6}$ \\
& & & & \\
\hline
\end{tabular}

The microstructural characterizations were performed on the ORNL energy compensated atom probe field ion microscope. Details of this instrument may be found elsewhere. ${ }^{5}$ The field ion micrographs were recorded with a specimen temperature of between 60 and $70 \mathrm{~K}$. All atom probe analyses were performed with a specimen temperature of 50 to $60 \mathrm{~K}$ and a pulse fraction of $20 \%$.

The amount of solute segregation at interfaces was estimated with the use of a method based on the Gibbsian interfacial excess. ${ }^{6.7}$ The Gibbsian interfacial excess ${ }^{8}$ of element $i, \Gamma_{i}$, may be determined directly from an atom probe analysis with the use of the following relationships:

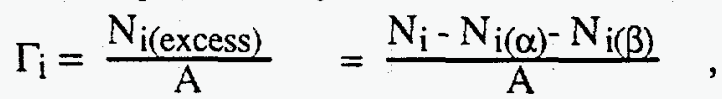

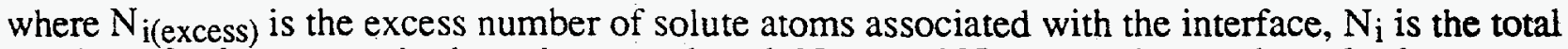
number of solute atoms in the volume analyzed, $N_{i(\alpha)}$ and $N_{i}(\beta)$, are the number of solute atoms in the two adjoining regions $\alpha$ and $\beta$ either side of the dividing surface, and $A$ is the interfacial area over which the interfacial excess is determined. All these parameters may be directly estimated for all elements in the steel. This method provides a fundamental estimate of the level of segregant at an interface.

\section{Predictions based on the McLean model of equilibrium segregation}

Since the parameters for phosphorus segregation are reasonably well established in steels,, 90 it is possible to compare the atom probe results with model predictions. In thermally aged or unirradiated material, the amount of phosphorus coverage at the boundary may be predicted from the McLean model of equilibrium segregation. ${ }^{11}$ The equilibrium concentration of solute at the boundary is given, for dilute solutions, by

$$
c_{b}=\frac{B c e^{-\Delta G / R T}}{1+B c e^{-\Delta G / R T}},
$$

where $\mathrm{c}$ is the solute content available for segregation, $\Delta \mathrm{G}$ is the free energy change associated with segregation to the boundary, $\mathrm{R}$ is the gas constant, and $\mathrm{T}$ is the absolute temperature. The constant $B$, the vibrational entropy of the grain boundary region, was assumed to be 1 . A free energy change of $\Delta G_{P}=-56,700+12.4 \mathrm{~T}$ was used in these calculations. ${ }^{12}$ The results of this model for the equilibrium coverage of phosphorus as a function of temperature for the nominal phosphorus levels in the steels are shown in Fig. 1.

The dependence of segregation after a quench from a high to a lower temperature as a function of time $t$ may also be predicted from the following relationship 


\section{DISCLAIMER}

Portions of this document may be illegible in electronic image products. Images are produced from the best available original document. 


$$
c_{b}(t)=c_{b}(\infty)-c\left(\alpha_{2}-\alpha_{1}\right) e^{4 D t / \alpha_{2}^{2} d^{2}} \quad \operatorname{erfc}\left\{\frac{2 \sqrt{D t}}{\alpha_{2} d}\right\}
$$

where $\alpha_{1}=c_{b}(\infty) / c$ at the low temperature, $\alpha_{2}=c_{b} / c$ at the high temperature just prior to quenching, $\mathrm{D}$ is the diffusion coefficient at the lower temperature, and $\mathrm{d}$ is the thickness of the boundary. Some examples of the increase in the phosphorus coverage at a boundary during a typical stress relief treatment in the A533B steel and the precipitation hardening stage of the heat treatment at $700^{\circ} \mathrm{C}$ are shown in Fig. 2. At these annealing temperatures, the phosphorus coverage increases rapidly attaining over $95 \%$ of the equilibrium value in $1 \mathrm{~h}$ and almost $99 \%$ after $10 \mathrm{~h}$ aging at $700^{\circ} \mathrm{C}$. The effects of a post-irradiation annealing treatment of $200 \mathrm{~h}$ at 400 and $475^{\circ} \mathrm{C}$ in the Russian $15 \mathrm{Kh} 2 \mathrm{MFA}$ Weld 37 steel and an A533B steel are shown in Fig. 3. The phosphorus coverage is predicted to increase by approximately 1.7 times in the $400^{\circ} \mathrm{C}$ treatment and by 3 times in the $475^{\circ} \mathrm{C}$ treatment. These simulations also indicate that these annealing treatments which were designed to eleviate the effects of copper precipitation have an undesirable side effect of generating significantly higher phosphorus levels at the boundary. The increase in phosphorus coverage during long term thermal aging $288^{\circ} \mathrm{C}$ is shown in Fig. 4. It should be noted that the predicted increase in phosphorus only accounts for the thermal component and does not include additional effects due to the neutron-irradiation during actual service in a nuclear reactor. These predictions indicate that the phosphorus coverage will continue to increase throughout the lifetime of the reactor. It should also be noted that the postirradiation anneal at $475^{\circ} \mathrm{C}$ may generate a higher phosphorus coverage than what is observed after 30 years of service at $288^{\circ} \mathrm{C}$.

\section{RESULTS AND DISCUSSION}

Some examples of field ion micrographs of decorated lath boundaries in the A533B and Russian steels are shown in Fig. 5. In both series of steels, the boundaries exhibit some brightly-imaging regions which were identified by selected area analysis in the atom probe to be ultrafine molybdenum carbonitride precipitates. Since the size of these precipitates was found to range up to only $\sim 1 \mathrm{~nm}$ in diameter, it was not experimentally possible to ascertain whether the phosphorus detected at the boundary was associated with the precipitates (either as a carbonitrophosphide or at the carbide-matrix interface) or simply as a boundary segregant. It is unlikely that these ultrafine precipitates would be detected by transmission electron microscopy. In the Russian steels, the coverage of these precipitates was found to decrease in the vicinity of the larger vanadium carbide precipitates that were also present along the lath boundaries. Although the coverage of these precipitates varied from a continuous film in some regions of certain materials to isolated precipitates in other segments of the boundary, it appears to be a general feature of both these types of molybdenum-containing pressure vessel steels.

The results of the atom probe determinations of the average phosphorus coverage at lath and grain boundaries are summarized and compared to the predictions of the McLean model of equilibrium segregation in Table 2. The results for all the unirradiated specimens are in good agreement with the predictions obtained from the McLean model of equilibrium segregation. Atom probe analyses of the matrix immediately adjacent to the boundary did not reveal elevated phosphorus levels and therefore the phosphorus segregation was indicative of monolayer-type segregation. In the case of the unirradiated Weld 37, an additional experiment was performed at a section of a lath boundary that was within $5 \mathrm{~nm}$ of a $10 \mathrm{~nm}$ thick lenticular vanadium carbide precipitate and yielded a much higher result of $24 \%$ phosphorus coverage. The neutronirradiated A533B and Weld 28 materials were also found to exhibit significantly higher levels of phosphorus coverage than their unirradiated varients.

It should be noted that in spite of the high phosphorus coverage of $11 \%$, unirradiated Weld 28 was found to be ductile at room temperature. It is therefore possible that the detrimental effect of phosphorus is to some extent compensated for by the presence of the molybdenum carbonitride film at the lath boundaries. Since precipitate-matrix interfaces are typically weaker than boundaries, it is unlikely that molybdenum carbonitride films would 


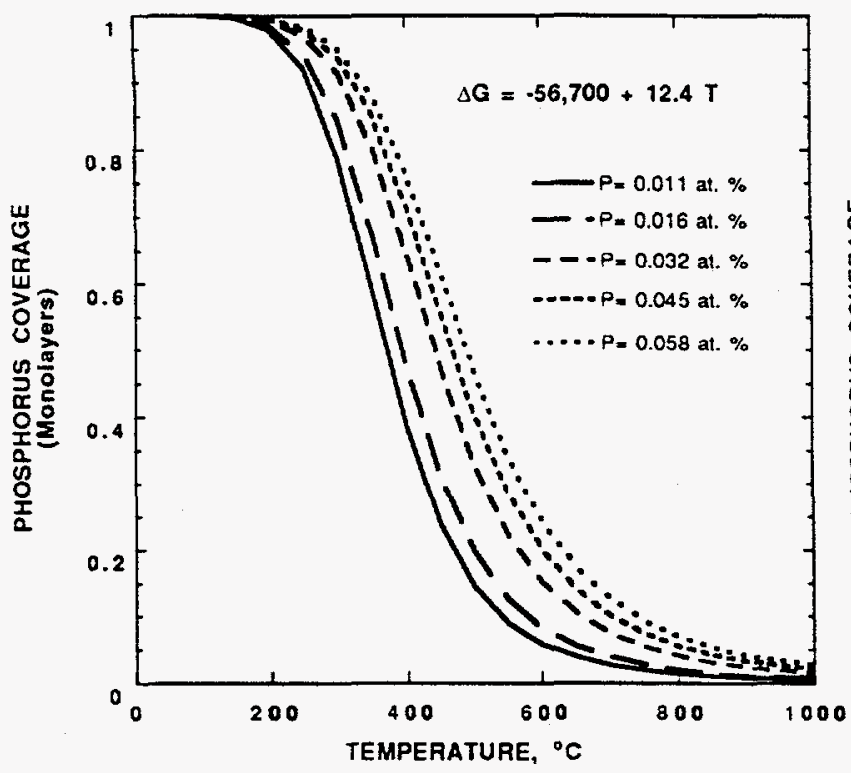

Fig. 1. Predicted equilibrium phosphorus coverage at boundaries for the 5 steels examined as a function of temperature.

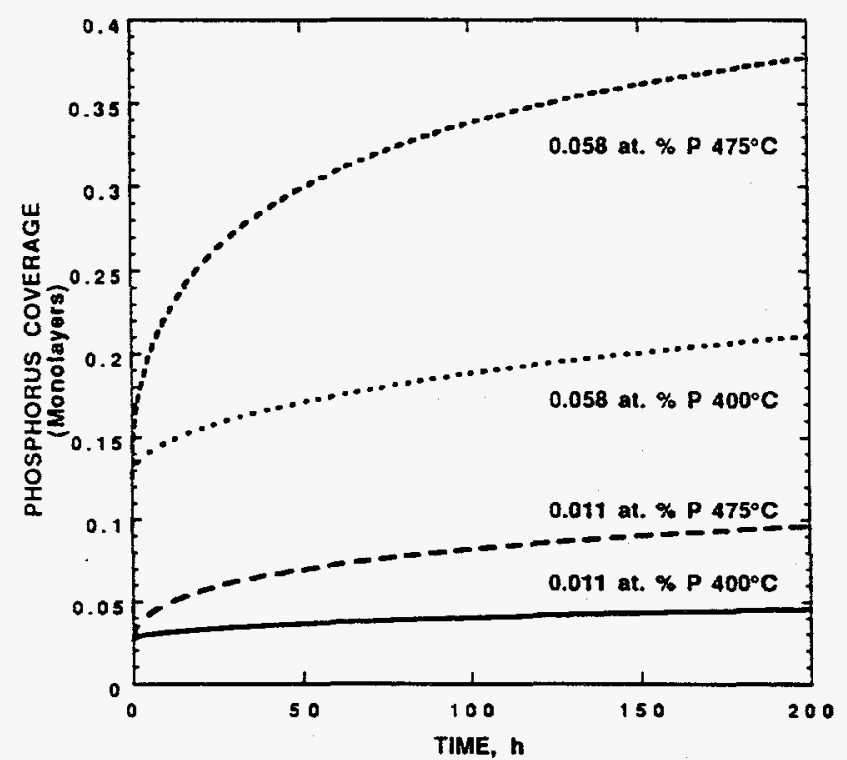

Fig. 3. Predicted increase in phosphorus coverage at boundaries during annealing at 400 and $475^{\circ} \mathrm{C}$.

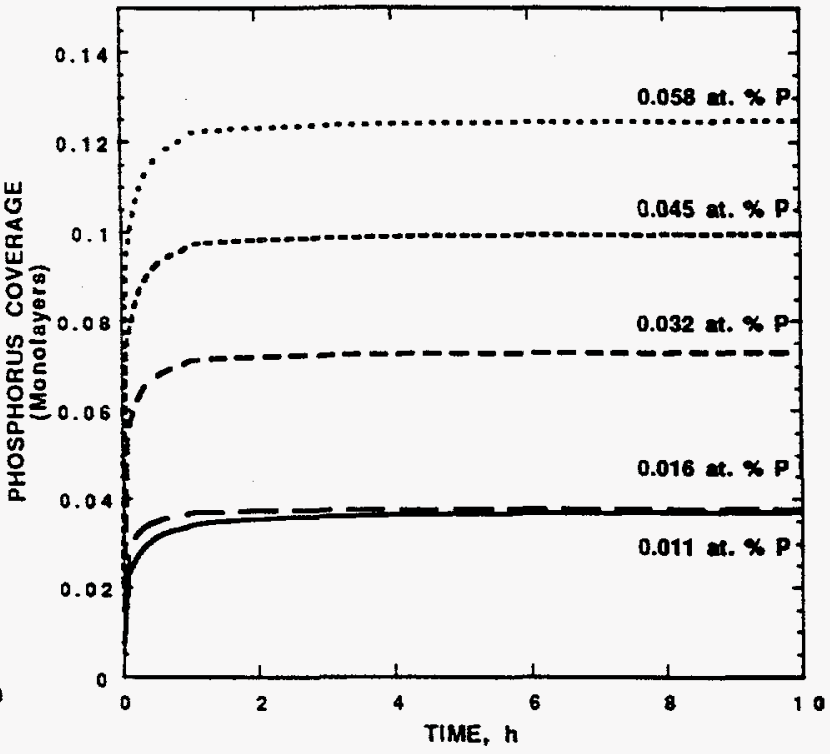

Fig. 2. Predicted increase in phosphorus coverage at boundaries during the precipitation hardening heat treatment at $700^{\circ} \mathrm{C}(\geq 0.016$ at. \% P $)$ or stress relief heat treatment at $650^{\circ} \mathrm{C}(0.011$ at. \% P)

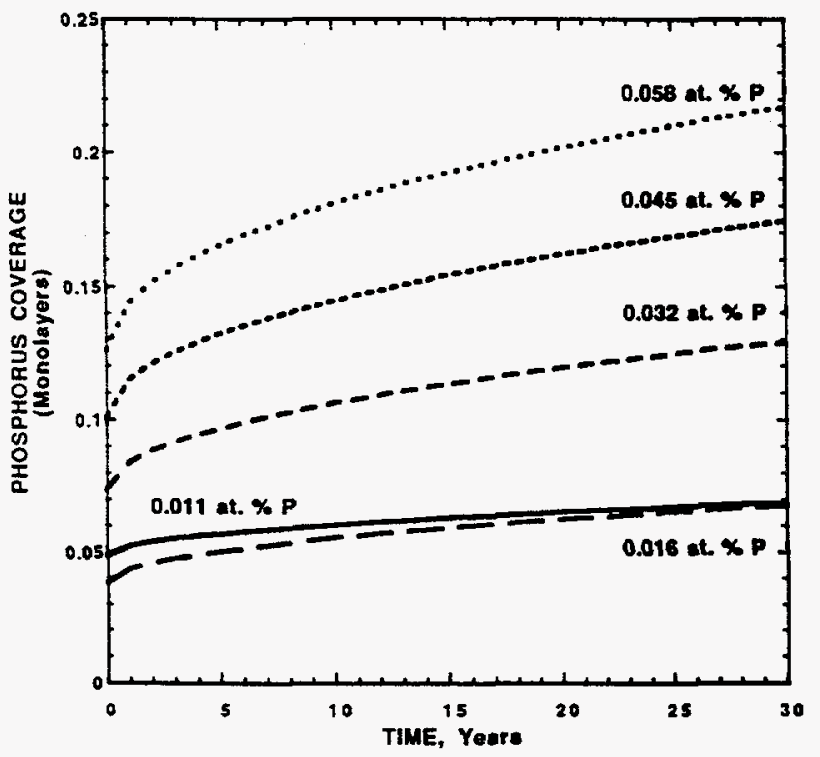

Fig. 4. Predicted increase in phosphorus coverage at boundaries after thermal aging at $288^{\circ} \mathrm{C}$ for 30 years. 
improve the cohesion of the boundary. However, the carbonitride film may play an important role in modifying the behavior of the phosphorus so that it does not cause temper embrittlement.

Table 2. Summary of the average phosphorus coverage at lath and grain boundaries as measured in the atom probe and predicted by the McLean model of equilibrium segregation.

\begin{tabular}{|c|c|c|c|c|c|}
\hline Material & $\begin{array}{c}\text { Fluence } \\
(\mathrm{n} \mathrm{cm}-2) \\
\mathrm{E}>1 \mathrm{MeV}^{-}\end{array}$ & $\begin{array}{c}\mathrm{P} \text { Content } \\
(\text { at. \%) }\end{array}$ & $\begin{array}{c}\Gamma_{\mathrm{i}} \\
\text { atoms cm-2 }\end{array}$ & $\begin{array}{c}\text { Coverage } \\
\text { (layers) }\end{array}$ & $\begin{array}{c}\text { Prediction } \\
\text { (layers) }\end{array}$ \\
\hline A533B & $\begin{array}{c}\text { Unirradiated } \\
1 \times 10^{19}\end{array}$ & $\begin{array}{l}0.011 \\
0.011\end{array}$ & $\begin{array}{c}5.7 \times 10^{13} \\
1.8 \times 10^{14}\end{array}$ & $\begin{array}{c}3 \% \\
10 \%\end{array}$ & $5 \%$ \\
VVER 440 & Unirradiated & 0.032 & $8.2 \times 10^{13}$ & $5 \%$ & $7 \%$ \\
VVER 1000 & Unirradiated & 0.016 & $1.3 \times 10^{14}$ & $8 \%$ & $5 \%$ \\
Weld 28 & Unirradiated & 0.045 & $2.0 \times 10^{14}$ & $11 \%$ & $10 \%$ \\
Weld 37 & Unirradiated & 0.058 & $2.8 \times 10^{14}$ & $13 \%$ & $12 \%$ \\
\hline
\end{tabular}

\section{Acknowledgments}

The authors would like to thank Profs. R. Odette and G.E. Lucas of the University of California - Santa Barbara and Dr. G. Brauer of KAI Inc. Berlin at Research Center Rossendorf Inc., Dresden, Germany for supplying some of the materials used in this study. Research sponsored by the Division of Materials Sciences, U.S. Department of Energy, under contract DE-AC05-84OR21400 with Martin Marietta Energy Systems Inc. and by the Office of Nuclear Regulatory Research, U.S. Nuclear Regulatory Commission under inter-agency agreement DOE 1886-8109-8L with the U.S. Department of Energy.

\section{References}

1. M.K. Miller and M.G. Burke, J. Nucl. Mater., 195 (1992) 68-82.

2. M.K. Miller, M.G. Hetherington and M.G. Burke, Metall. Trans., 20 A (1989) 2651-2661.

3. M.K. Miller and G.D.W. Smith, Atom Probe Microanalysis: Principles and Applications

to Materials Science, (Materials Research Society, Pittsburgh, PA, 1989).

4. M.K. Miller, R. Jayaram and K.F. Russell, J. Nucl. Mater., in press.

5. M.K. Miller, J. de Physique, 47 (1986) C2-493-498.

6. B.W. Krakauer and D.N. Seidman, Phys. Rev. B, 48, (1993) 6724.

7. M.K. Miller and G.D.W. Smith, Appl. Surf. Sci., in press.

8. J.W. Gibbs, The Collected Works of J. Willard Gibbs, vol. I, (Yale University Press, New Haven, CT, 1948).

9. I. A. Vatter, C.A. Hippsley and S.G. Druce, Int. J. Pres. Ves. and Piping, 54 (1993) 31-48.

10. S.G. Druce, G. Gage and G. Jordan, Acta Metall., 34 (1986) 641-652.

11. D. McLean, Grain Boundaries in Metals, (Oxford University Press, London, 1957), p. 116.

12. I.A. Vatter and C.A. Hippsley, to be published.

\section{DISCLAIMER}

This report was prepared as an account of work sponsored by an agency of the United States This report was prepared an an their Government. Neither the United States Government nor any agency theref, nor any of their employees, makes any warranty, express or implied, or assumes any legal liabily or resper, or bility for the accuracy, completeness, or usefulness of any information, appaned rights. Referprocess disclosed, or represents that its use would not infringe privately owned trademark, ence herein to any specific commercial product, process, or service by trade name, trademark, manufacturer, or otherwise does not necessarily constitute or imply its endorsement, recommendation, or favoring by the United States Government or any agency thereof. The views and opinions of authors expressed herein do not 

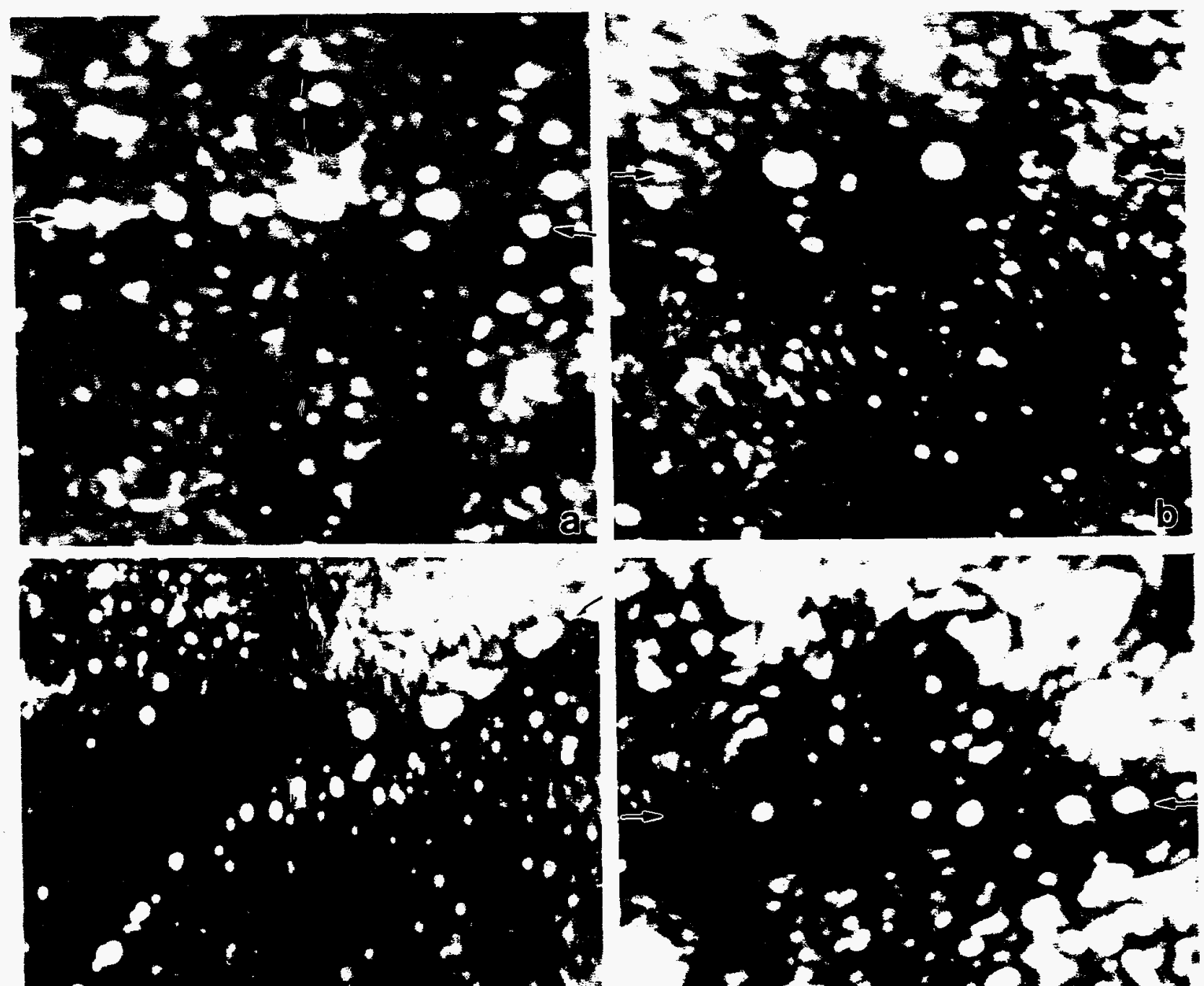

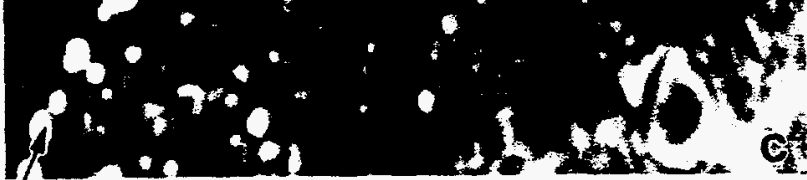
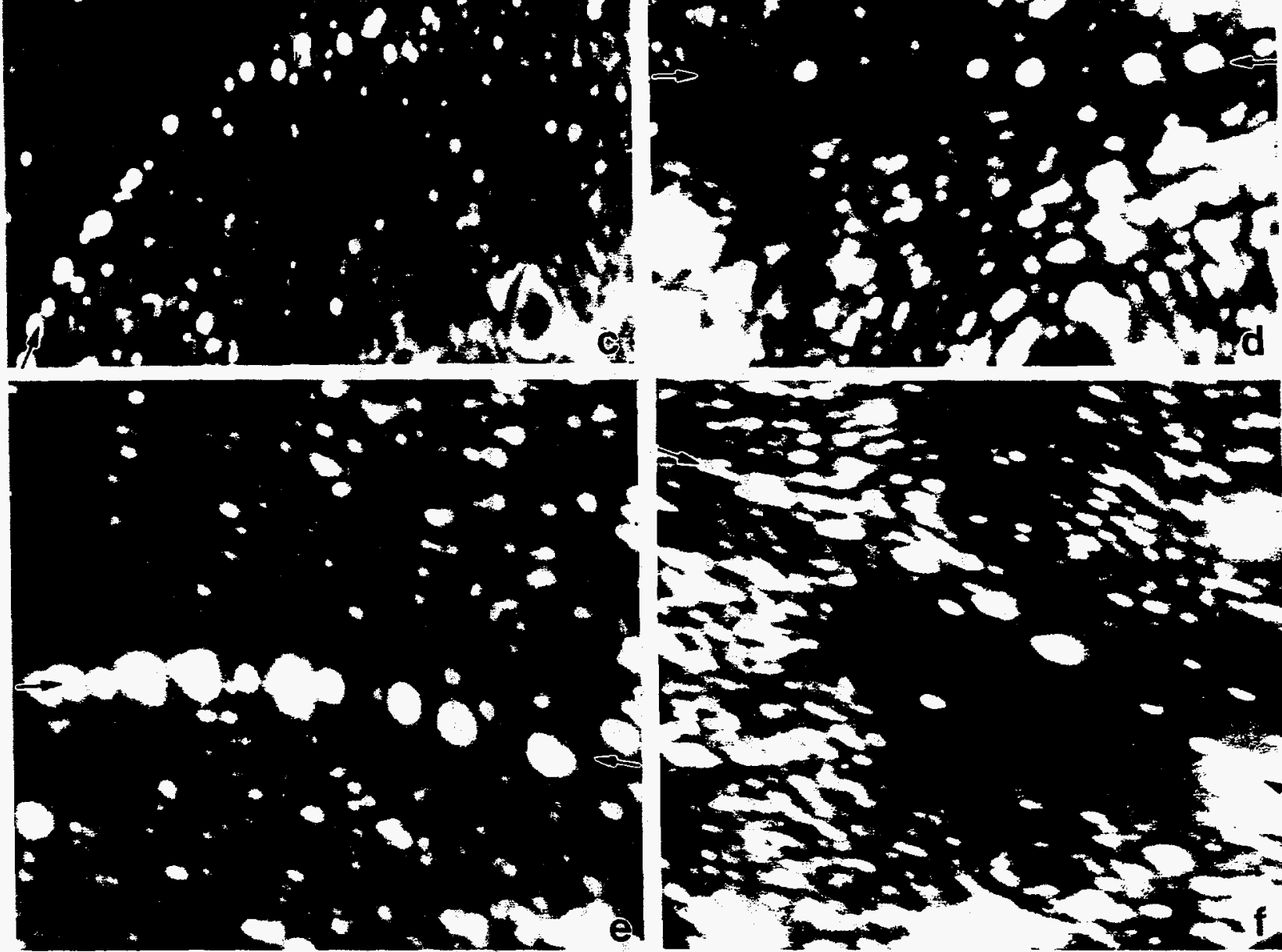

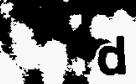
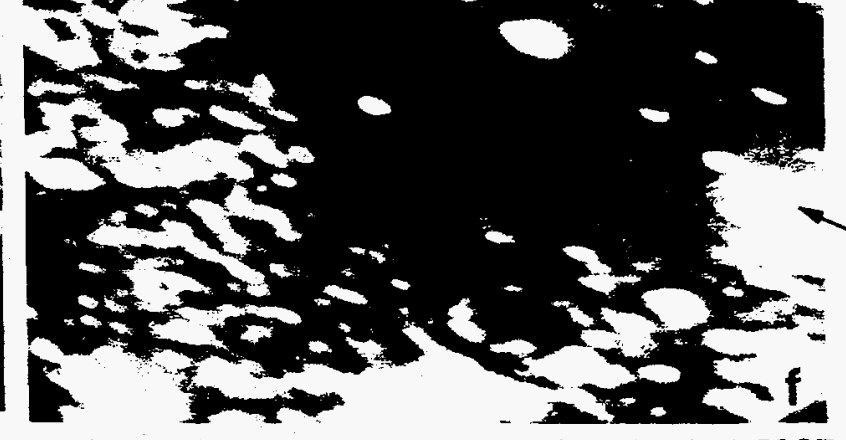

Fig. 5. Field ion micrographs of decorated boundaries in a) A533B unirradiated, b) A533B neutron-irriadiated, c) VVER 440 unirradiated, d) Weld 37 unirradiated, e) Weld 28 unirradiated, and f) Weld 28 neutron-irradiated. 